\title{
Molecular crosstalk between ferroptosis and apoptosis: emerging role of ER stress-induced p53-independent PUMA expression
}

\author{
Se Hoon Hong ${ }^{1, *}$, Dae-Hee Lee ${ }^{2,3, *}$, Young-Sun $\mathrm{Lee}^{1}$, Min Jee $\mathrm{Jo}^{2}$, Yoon A Jeong ${ }^{2}$, \\ William T. Kwon ${ }^{1}$, Haroon A. Choudry ${ }^{1}$, David L. Bartlett ${ }^{1}$ and Yong J. Lee ${ }^{1}$ \\ ${ }^{1}$ Department of Surgery, School of Medicine, University of Pittsburgh, Pittsburgh, PA 15213, USA \\ ${ }^{2}$ Brain Korea 21 Program for Biomedicine Science, Korea University College of Medicine, Korea University, Seoul 02841, \\ Republic of Korea \\ ${ }^{3}$ Division of Oncology/Hematology, Department of Internal Medicine, College of Medicine, Korea University Medical Center, \\ Korea University, Seoul 08308, Republic of Korea \\ "These authors have contributed equally to this work \\ Correspondence to: Yong J. Lee, email: leeyj@upmc.edu \\ Keywords: ferroptosis; apoptosis; PUMA; ER; p53 \\ Received: August 15, $2017 \quad$ Accepted: November 26, $2017 \quad$ Published: December 08, 2017 \\ Copyright: Hong et al. This is an open-access article distributed under the terms of the Creative Commons Attribution License 3.0 \\ (CC BY 3.0), which permits unrestricted use, distribution, and reproduction in any medium, provided the original author and source \\ are credited.
}

\section{ABSTRACT}

Ferroptosis is a type of programmed cell death that depends on iron and is characterized by the accumulation of lipid peroxides. In the present study, we investigated the nature of the interplay between ferroptosis and other forms of cell death such as apoptosis. Human pancreatic cancer PANC-1 and BXPC-3 and human colorectal cancer HCT116 cells were treated with ferroptotic agents such as erastin and artesunate (ART) in combination with the apoptotic agent tumor necrosis factorrelated apoptosis-inducing ligand (TRAIL). We observed synergistic interaction of erastin or ART with TRAIL as determined by cell death assay, caspase activation, poly [ADP-ribose] polymerase 1 (PARP-1) cleavage, flow cytometry analysis, and lipid peroxidation assay. Moreover, erastin and ART induced endoplasmic reticulum (ER) stress and promoted p53 upregulated modulator of apoptosis (PUMA) expression via C/EBP-homologous protein (CHOP). Synergy of erastin/ART and TRAIL was abolished in PUMA-deficient HCT116 cells and CHOP-deficient mouse embryonic fibroblasts, but not in p53-deficient HCT116 cells. The results suggest the involvement of the p53independent CHOP/PUMA axis in response to ferroptosis inducers, which may play a key role in ferroptotic agent-mediated sensitization to TRAIL-induced apoptosis.

\section{INTRODUCTION}

Several processes such as ferroptosis, apoptosis, necrosis, and autophagy are the primary mechanisms of cell death. Each type of biological death leaves a biochemical and morphological fingerprint [1]. However, emerging evidence suggests that these different types of cell death often share common pathways [2].

Ferroptosis is a unique iron-dependent form of regulated cell death [3]. The term was coined in 2012 by studies identifying several genes responsible for ferroptosis, including those associated with amino acids such as glutamate and cysteine, and lipid metabolism [4-6]. Ferroptosis triggered by these genes can be inhibited by chemical compounds such as the cystine/glutamate antiporter (System $\mathrm{X}_{\mathrm{C}}{ }^{-}$) inhibitor erastin, the glutathione (GSH) synthesis inhibitor buthionine sulfoximine (BSO), the glutathione-dependent antioxidant enzyme glutathione peroxidase 4 (GPX4) inhibitor (1S, 3R)-RSL3, and the glutathione S-transferase inhibitor artesunate (ART) [3, 7-11]. Iron-dependent accumulation 
of lipid reactive oxygen species (ROS) and depletion of plasma membrane polyunsaturated fatty acids have been well known to result in this lethal event [3, 4, 12, 13]. Differences in genetic makeup among cancer cells affect the pharmacodynamic response of ferroptotic agents. High level RAS-RAF-MEK pathway activity or p53 expression may elevate generation of ROS through mitochondrial voltagedependent anion channel 2/3 (VDAC2/3) or inhibit cystine uptake, respectively, and sensitize cancer cells to ferroptosis [14-19]. Conversely, iron chelators (e.g., deferoxamine) and lipid peroxidation inhibitors (e.g., liproxstatin, ferrostatin, and zileuton) are known to suppress ferroptosis and block pathological cell death events in the brain, kidney, and other tissues [10, 20-23].

Since its discovery in 1995, tumor necrosis factorrelated apoptosis-inducing ligand (TRAIL) has sparked growing interest among oncologists due to its remarkable ability to induce apoptosis in malignant human cells, but not in most normal cells [24, 25]. TRAIL initiates the extrinsic pathway by binding to death receptors (DRs) such as DR4 and DR5 and induces the apoptotic signal. Activation of death domains (DDs) leads to formation of the death-inducing signaling complex (DISC) [26]. Caspase- 8 recruitment and its activation at the DISC leads to further triggering of signaling molecules downstream, which results in the activation of executioner caspase-3, -6 , and -7 , which culminates in apoptotic death [27]. Activated caspase-8 also cleaves a pro-apoptotic molecule, Bid; truncated Bid (tBid) translocates to the mitochondria and induces Bax (Bcl-2-associated X protein) and Bak (Bcl-2 homologous antagonist killer) oligomerization $[28,29]$. Oligomerized Bax and Bak's insertion into the mitochondrial outer membrane, permeabilization, and depolarization of the mitochondria promote cytochrome $c$ release [30]. Released cytochrome $c$ facilitates the formation of the Apaf1 (apoptosis signal-regulating kinase)/caspase-9 apoptosome, which activates caspase-9 and subsequently, caspase-3 [31].

TRAIL-induced cytotoxicity can be modulated by various agents such as chemotherapeutic drugs [32-34], ionizing radiation [35], other cytokines [36], and matrix metalloprotease inhibitors [37]. In this study, we observed a synergistic interaction between TRAIL and ferroptotic agents. A combined treatment of ART/erastin with TRAIL markedly enhanced TRAIL-induced apoptosis. Our studies suggest that these synergistic effects are due to endoplasmic reticulum (ER) stress-induced p53-independent PUMA (p53 upregulated modulator of apoptosis) expression.

\section{RESULTS}

\section{Ferroptosis inducers ART and erastin enhance TRAIL-induced apoptosis}

To determine whether ferroptotic agents are cytotoxic to human cancer cells, human pancreatic cancer PANC-1 and BxPC-3 and human colon cancer HCT116 cells were treated with various doses of ART. We observed dosedependent effects of ART on cytotoxicity (Figure 1). Next, we examined the effect of combinatorial treatment (ART + TRAIL) on cytotoxicity. As shown in Figure 1A-1C, a synergistic cytotoxic effect was observed with the combinatorial treatment compared with any single treatment $(p<0.001)$. Confirmation was obtained by combination index $(\mathrm{CI})$ analysis as shown in Table 1; there was strong or moderate synergy of ART in combination with TRAIL, especially in the high dose group in the three cell lines. We further investigated whether the combinatorial treatment-induced cytotoxicity was associated with apoptosis. Data from the immunoblotting assay demonstrate that the synergistic effects were due to an increased activation (cleavage) of caspase 8/9/3 and thus, the hallmark feature of apoptosis, PARP (poly (ADP-ribose) polymerase) cleavage (Figure 1D-1F). Similar results were observed with erastin in combination with TRAIL-treated HCT116 cells. We observed a dose-dependent apoptotic effect of TRAIL and ferroptotic effect of erastin (Figure 2A and $2 \mathrm{~B}$ ). The synergistic cytotoxicity was observed when cells were treated with erastin in combination with TRAIL (Figure 2C and Table 1). Data from the immunoblotting assay and flow cytometry assay demonstrate that the combined treatment-induced cytotoxicity was associated with apoptosis as evident by increased PARP cleavage (Figure 2C) and apoptotic cells at the upper right quadrant of the plots (Figure 2D). An increase in apoptosis was also observed in BxPC-3 cells during treatment with TRAIL and erastin (Figure 2E). These results indicate that synergistic induction of cytotoxicity by combined treatment of erastin or ART with TRAIL is mediated by an increase in apoptosis.

\section{Ferroptotic agent-induced lipid peroxidation is not changed or influenced by the combination treatment of erastin or ART with TRAIL}

Since we observed that the combinatorial treatmentinduced synergistic cytotoxicity was due to an increase in apoptosis, we examined whether the combinatorial treatment enhances ferroptosis by analysis of malondialdehyde (MDA), a lipid peroxidation marker. As shown in Figure 3A, 3B and 3D, ferroptotic agents, but not TRAIL, induced lipid peroxidation in a dose-dependent manner in HCT116 cells. The combined treatment of TRAIL and erastin/ART did not enhance ferroptotic agentinduced lipid peroxidation (Figure 3C and 3E). Similar results were observed in BxPC-3 cells (Figure 3F). Similar to the lipid peroxidation result, erastin, but not TRAIL, induced heme oxygenase-1 (HO-1) expression, a marker of oxidative stress, in a dose-dependent manner (Figure 3B). The combined treatment of TRAIL and erastin did not enhance ferroptotic agent-induced HO-1 expression. 


\section{Ferroptotic agents induce ER stress}

Previous studies have shown that inhibition of cystine-glutamate exchange by ferroptotic agents leads to activation of an ER stress response and upregulation of the CHACl (glutathione-specific gammaglutamylcyclotransferase 1) gene [38,39]. Data from microarray assay studies (Figure 4A) also reveal that the ferroptotic agent ART promotes the ER stress marker ATF4 (activating transcription factor 4)-dependent gene expression such as TRB3 (tribbles homolog 3 ) and CHOP (C/EBP-homologous protein) [40]. Ferroptotic agent-induced ER stress was confirmed by detecting the unfolded protein response (UPR) by
A
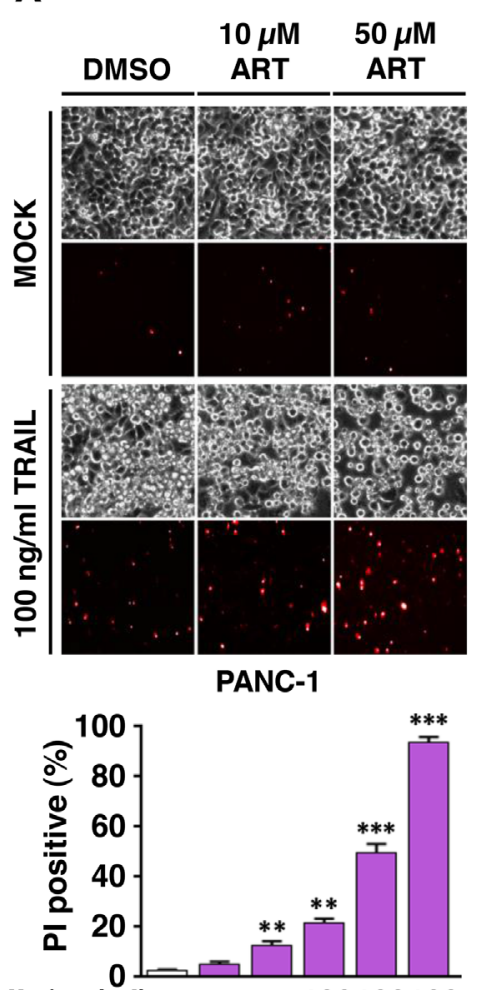

TRAIL (ng/ml) - - $\quad 10010010$ ART $(\mu \mathrm{M})-1050-1050$

D

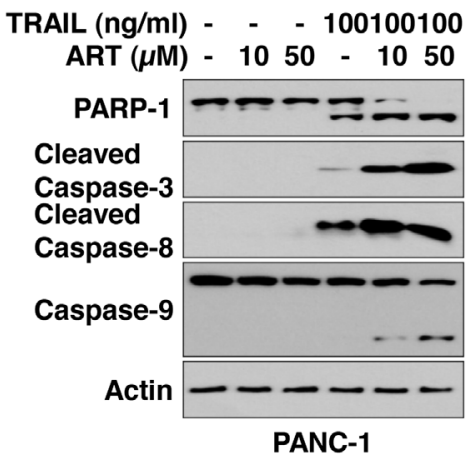

B
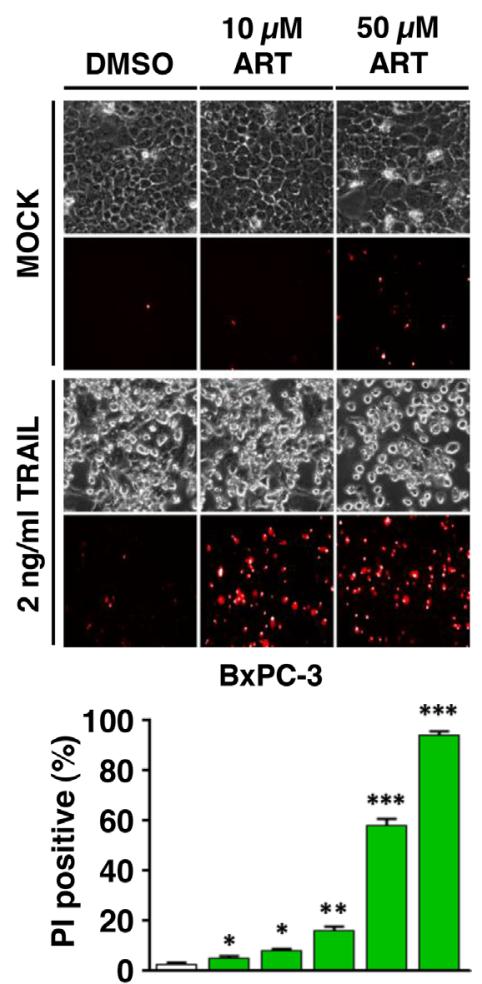

$\operatorname{ART}(\mu \mathrm{M})=1050-1050$

E

TRAIL (ng/ml) - - $\quad 2 \quad 22$ ART $(\mu \mathrm{M})$ - 1050 - 1050

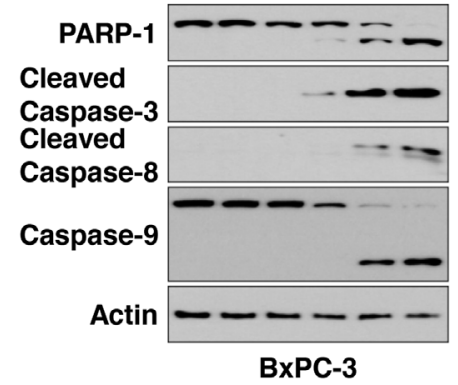

C
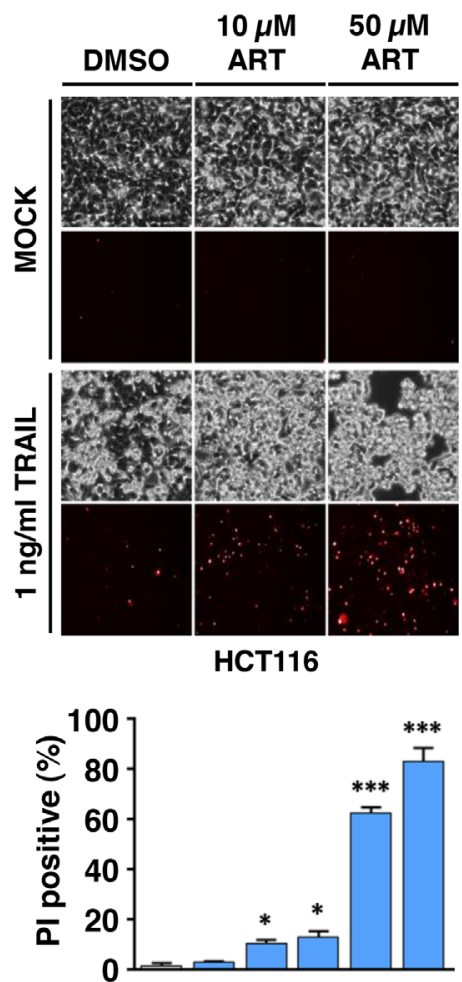

AIL $(\mathrm{ng} / \mathrm{ml})-\left[\begin{array}{cccc}- & - & 1 & 1\end{array}\right.$ ART $(\mu \mathrm{M})-1050-1050$
F

TRAIL (ng/ml) - $\quad-\quad-\quad \begin{array}{lll}1 & 1 & 1\end{array}$ ART $(\mu \mathrm{M})=1050-1050$

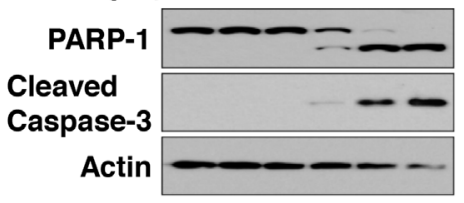

HCT116

Figure 1: Artesunate (ART) promotes TRAIL-induced apoptosis. (A-F) PANC-1 (A), BxPC-3 (B), and HCT116 (C) cells were pretreated with ART (10 or $50 \mu \mathrm{M}$ ) for $20 \mathrm{~h}$ and then exposed to TRAIL (PANC-1, $100 \mathrm{ng} / \mathrm{ml}$; BxPC-3, $2 \mathrm{ng} / \mathrm{ml}$; HCT116, $1 \mathrm{ng} / \mathrm{ml}$ ) for an additional $4 \mathrm{~h}$. The cells were stained with propidium iodide (PI). Phase-contrast images or fluorescence images were visualized under a light or fluorescence microscope, respectively (upper panels). Representative images are shown (magnification, X200). Cell death was determined by counting PI-stained cells and plotted (lower panels). Error bars represent the mean \pm SD from triplicate experiments. For statistical analysis, Student's $t$-test (two-sided, paired) was used. $p$-values: ${ }^{*}, 0.05 ;{ }^{* *}, 0.01 ;{ }^{* * *}, 0.001$. Cell lysates of PANC-1 (D), BxPC-3 (E), and HCT116 (F) cells were analyzed with immunoblotting assay using indicated antibodies. 
Table 1: Combination index (CI) for ART/erastin and TRAIL

\begin{tabular}{lccccc}
\hline & Combination therapy & & Combination index (CI) \\
\cline { 1 - 2 } TRAIL $(\mathbf{n g} / \mathbf{m l})$ & Erastin $(\mu \mathrm{M})$ & ART $(\mu \mathrm{M})$ & & HCT116 \\
\hline 1 & 10 & - & $0.327^{* *}$ \\
1 & 50 & - & $0.161^{* * *}$ \\
1 & - & 10 & $0.301^{* *}$ \\
1 & - & 50 & $0.367^{* *}$ \\
\hline
\end{tabular}

*: slight synergy; ${ }^{* *}$ : moderate synergy; ${ }^{* * *}$ : strong synergy

A

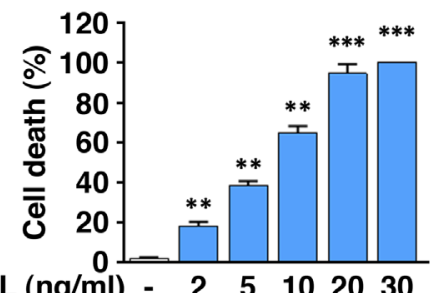

TRAIL (ng/ml) - $2 \begin{array}{lllll}5 & 10 & 20 & 30\end{array}$

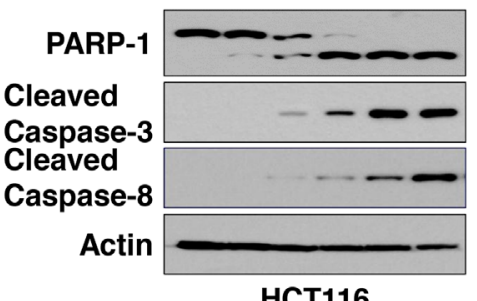

D

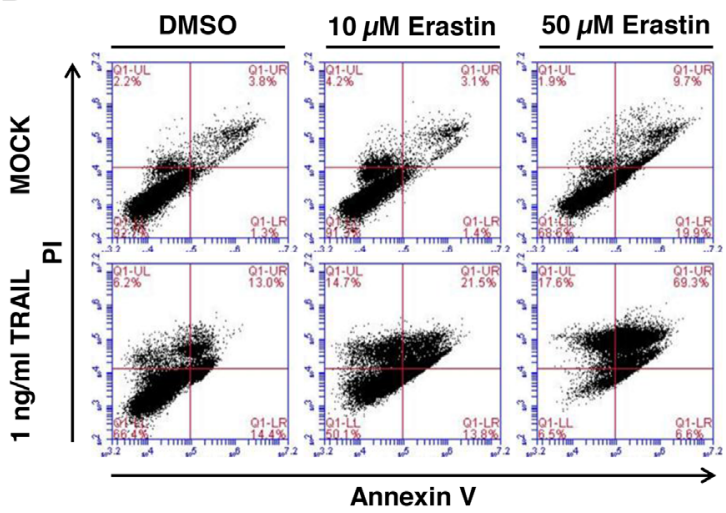

B

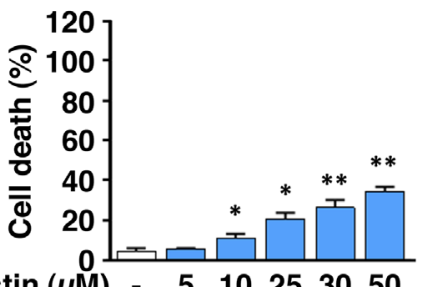

Erastin $(\mu \mathrm{M})-510253050$

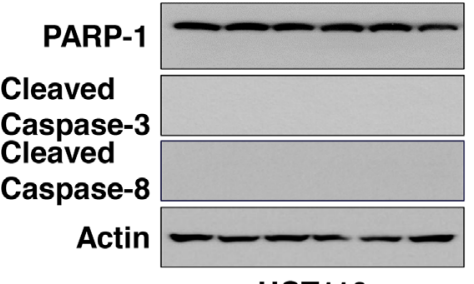

HCT116
C

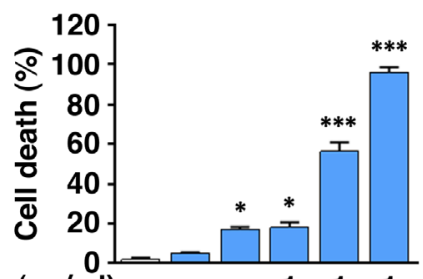

TRAIL (ng/ml) - $\quad-\quad \begin{array}{llll} & 1 & 1 & 1\end{array}$

Erastin $(\mu \mathrm{M})-1050-1050$

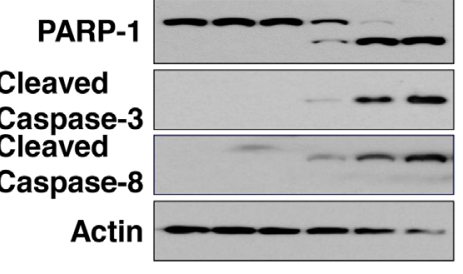

HCT116

E

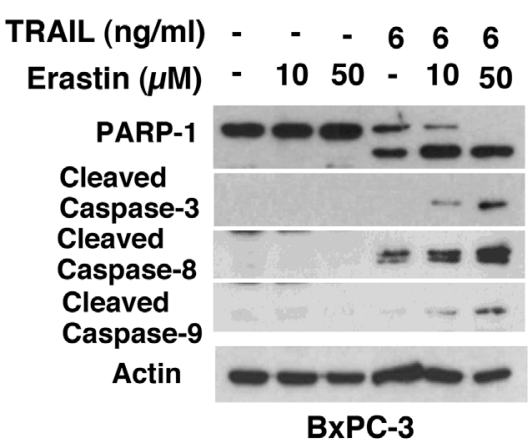

Figure 2: Erastin promotes TRAIL-induced apoptosis. (A and B) HCT116 cells were treated with various doses of erastin for $24 \mathrm{~h}$ (A) or TRAIL for $4 \mathrm{~h}$ (B) and then the cell death rate was determined, respectively (upper panels). Cell lysates were analyzed with immunoblotting assay using indicated antibodies (lower panels). (C and D) HCT116 cells were pretreated with erastin (10 or $50 \mu \mathrm{M})$ for $20 \mathrm{~h}$ and then exposed to TRAIL $(1 \mathrm{ng} / \mathrm{ml})$ for an additional $4 \mathrm{~h}$. Cell death was determined by counting and plotted. Whole-cell extracts were then analyzed with immunoblotting assay using indicated antibodies (C). The cells were stained with annexin V and PI and then analyzed using flow cytometry (D). (E) BxPC-3 cells were pretreated with erastin (10 or $50 \mu \mathrm{M})$ for $20 \mathrm{~h}$ and then exposed to TRAIL (6 ng/ $\mathrm{ml}$ ) for an additional $4 \mathrm{~h}$. Whole-cell extracts were then analyzed with immunoblotting assay using indicated antibodies. 
using the anti-ubiquitinylated protein antibody FK2 antibody. Immunoblotting analysis showed that ARTor erastin-treated HCT116 cells contained a higher level of ubiquitin conjugates compared with untreated control cells (Figure 4B). In particular, inhibition of proteasomal degradation flux with MG132 clearly revealed an increase in ubiquitinated proteins in ARTor erastin-treated cells (Figure 4B). These results imply that the UPR occurs during treatment with the ferroptotic agents ART and erastin. Next, we detected ferroptotic agent-induced ER stress by using ER stress markers such as GRP78 (78 kDa glucose-regulated protein) and CHOP. As shown in Figure 4C-4E, a ferroptotic agent-induced ER stress response occurred in a time- and dose-dependent manner. A combined treatment of TRAIL and erastin did not alter the ER stress response (Figure 4F).
Inhibition of ferroptotic agent-induced lipid peroxidation by ferrostatin-1 and liproxstatin-1 neither blocks the ER stress response nor suppresses the combined treatment of erastin or ART with TRAIL-induced synergistic cytotoxicity

We examined whether ferroptotic lipid peroxidation inducing agents play a role in ER stress and the combinatorial treatment-induced synergistic cytotoxicity. To examine this possibility, HCT116 cells were treated with erastin/ART in the absence/presence of the iron chelator deferoxamine (DFO), the lipid peroxidation inhibitors ferrostatin-1 (Fer-1), and liproxstatin-1 (Lip-1). Figure 5A and 5B show that Fer-1 and Lip-1 inhibited erastin/ART-induced lipid peroxidation, but not ER stress. DFO also inhibited erastin-induced lipid peroxidation, but not ER stress. However, unlike erastin,
A

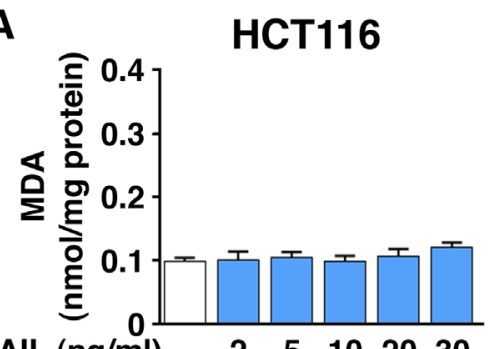

TRAIL (ng/ml) - $2 \quad 5 \quad 102030$

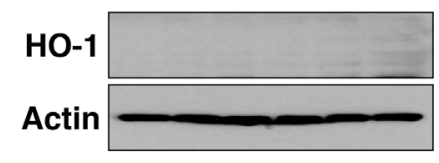

D

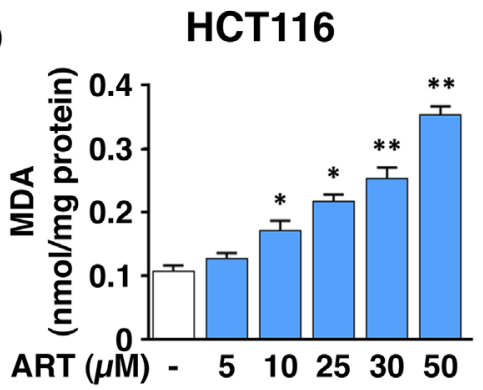

B
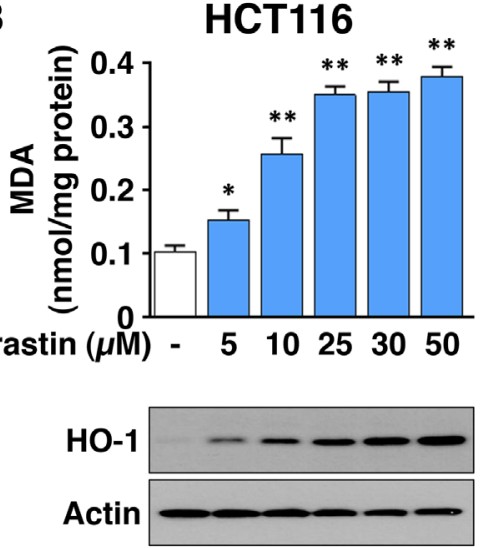

C

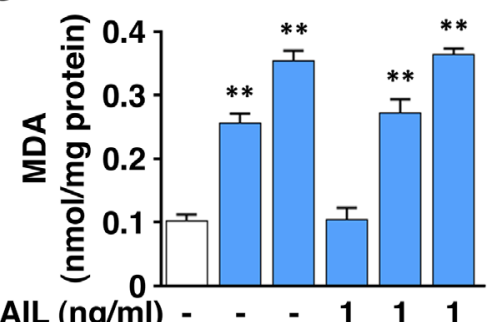

TRAIL $(\mathrm{ng} / \mathrm{ml})-\quad-\quad-\quad 111$

Erastin $(\mu \mathrm{M})-1050-1050$

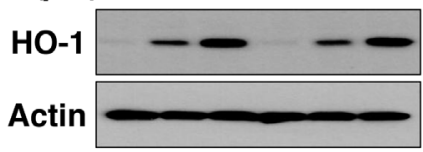

E

HCT116

$\mathbf{F}$
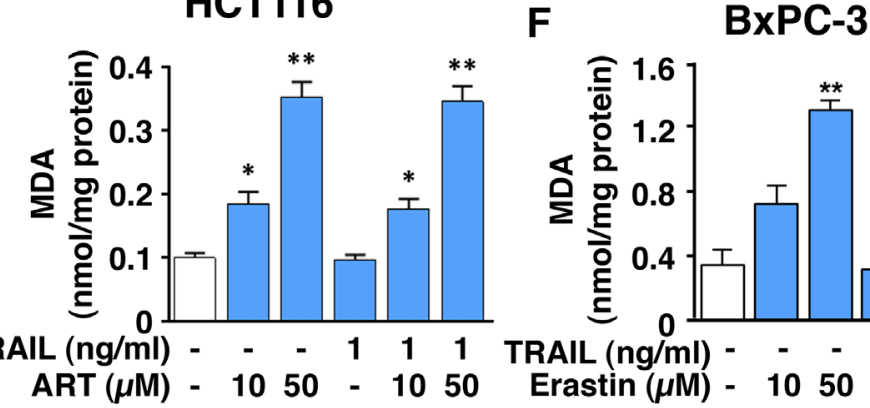

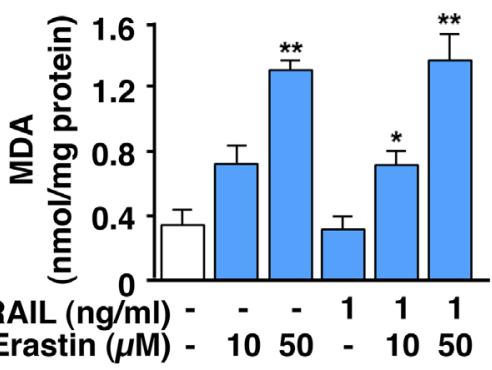

Figure 3: ART and erastin, but not TRAIL, induce lipid peroxidation. (A-C) HCT116 cells were treated with various doses of erastin for $24 \mathrm{~h}$ (A) or TRAIL for $4 \mathrm{~h}(\mathrm{~B})$. Cells were pretreated with erastin (10 or $50 \mu \mathrm{M})$ for $20 \mathrm{~h}$ and then exposed to TRAIL (1 ng/ml) for an additional $4 \mathrm{~h}(\mathrm{C})$. Lipid peroxidation (upper panels) and heme oxygenase (HO-1, lower panels) levels were analyzed by malondialdehyde (MDA) assay and immunoblotting assay, respectively. (D and E) HCT116 cells were treated with various doses of ART (D) or pretreated with ART $(10$ or $50 \mu \mathrm{M})$ for $20 \mathrm{~h}$ and then exposed to TRAIL (1 ng/ml) for additional $4 \mathrm{~h}$ (E). (F) BxPC-3 cells were pretreated with erastin $(10$ or $50 \mu \mathrm{M})$ for $20 \mathrm{~h}$ and then exposed to TRAIL (1 ng/ml) for additional $4 \mathrm{~h}$. MDA levels were determined and plotted. Error bars represent the mean \pm SD from triplicate experiments. For statistical analysis, Student's $t$-test (two-sided, paired) was used. $p$-values: ${ }^{*}, 0.05 ;{ }^{* *}, 0.01$. 
ART-induced ER stress was inhibited by treatment with DFO. DFO, Fer-1, and Lip-1, but not the caspase inhibitor $\mathrm{Z}-\mathrm{VAD}$, protected cells from ferroptosis (data not shown) and did not prevent the combinatorial treatment of erastin and TRAIL-induced synergistic cytotoxicity (Figure 5C). Similar results were observed with Fer-1 and Lip-1 on ARTand TRAIL-treated cells (Figure 5D). Unlike erastin and TRAIL-induced synergistic cytotoxicity, ART- and TRAILinduced synergistic cytotoxicity was inhibited by treatment with DFO. These results indicate that ER stress plays an important role in ferroptotic agent and TRAIL-induced synergistic cytotoxicity.

\section{Ferroptotic agent induces PUMA expression}

Previous studies show that CHOP binds to the proapoptotic protein PUMA (p53 upregulated modulator of apoptosis) promoter during ER stress and induces PUMA expression [41]. CHOP also induces several other proapoptotic proteins such as NOXA (Latin for damage) and
BIM $[42,43]$. Figure 6 shows that the ferroptotic agent ART induces PUMA expression in three different cancer cell lines. The combinatorial treatment of TRAIL and ART either maintained or enhanced the ER stress response. However, unlike PUMA, we either failed to detect NOXA expression in BxPC-3 cells or did not observe an increase in NOXA expression during ART treatment in HCT116 cells (Figure 6B and $6 \mathrm{C}$ ). We did not observe an increase in BIM expression during erastin treatment in HCT116 cells. Unlike erastin, the DNA damaging agent mitomycin $\mathrm{C}$ induced three isoforms of BIM: $\mathrm{BIM}_{\mathrm{EL}}, \mathrm{BIM}_{\mathrm{L}}$, and $\mathrm{BIM}_{\mathrm{S}}($ Figure $6 \mathrm{D})$.

\section{Ferroptotic agent promotes TRAIL-induced apoptosis via the p53-independent CHOP/PUMA pathway}

We further examined the role of ER stressassociated CHOP and PUMA expression in synergistic apoptosis during the combinatorial treatment of ART and TRAIL. For this study, we employed a CHOP knockout

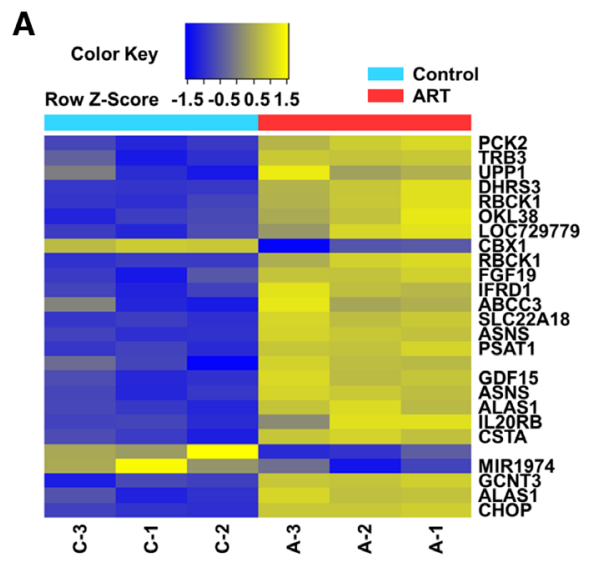

B

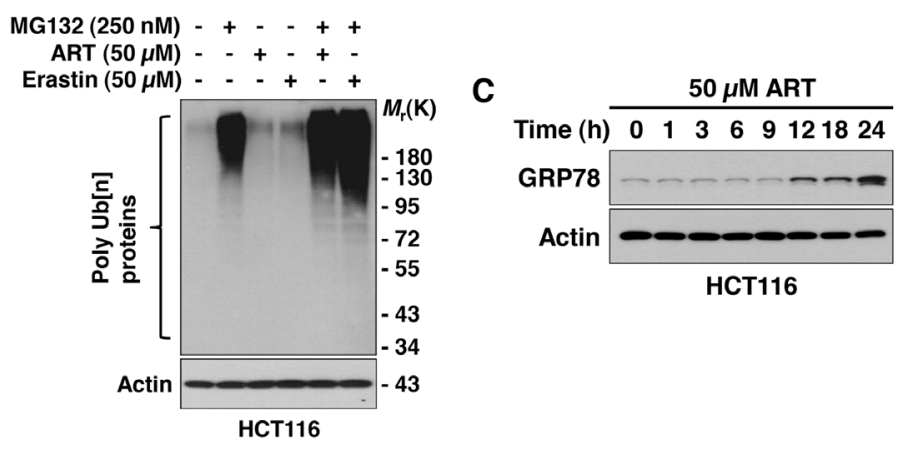

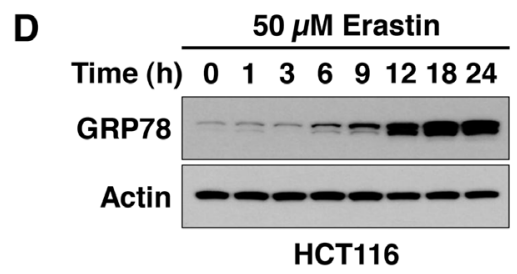

E

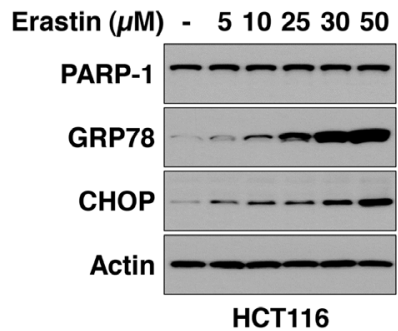

F

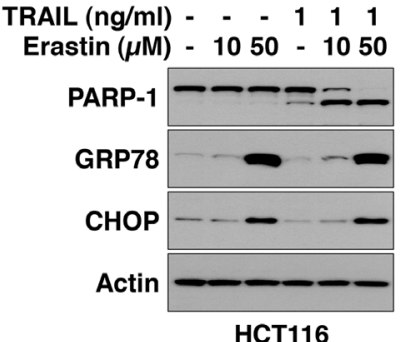

Figure 4: Ferroptotic agents induce ER stress in HCT116 cells. (A) Microarray assay for detection of ART-induced gene expression. Cells were treated with $50 \mu \mathrm{MART}$ for $24 \mathrm{~h}$ and triplicate Illumina gene expression microarrays were performed with BeadArray microarray technology. (B) Ferroptotic agents induce the unfolded protein response (UPR). Cells were treated with $50 \mu \mathrm{M}$ ART or $50 \mu \mathrm{M}$ erastin for $24 \mathrm{~h}$ in the presence/absence of $250 \mathrm{nM}$ MG132. Cell lysates were subjected to immunoblotting analysis using FK2 antibody specific to ubiquitin-conjugated proteins. Actin was used to confirm equal amounts of proteins loaded in each lane. (C and D) Cells were treated with ART $(50 \mu \mathrm{M}, \mathrm{B})$ or erastin $(50 \mu \mathrm{M}, \mathrm{C})$ for various times $(1-24 \mathrm{~h})$. Whole-cell extracts were analyzed with immunoblotting assay using indicated antibodies. (E) Cells were treated with various doses of erastin for $24 \mathrm{~h}$. Whole-cell extracts were analyzed using immunoblotting assay with indicated antibodies. (F) Cells were treated with erastin alone (10 or $50 \mu \mathrm{M})$ for $24 \mathrm{~h}$, TRAIL (1 ng/ml) alone for $4 \mathrm{~h}$, or pretreated with erastin $(10$ or $50 \mu \mathrm{M})$ for $20 \mathrm{~h}$ and then exposed to TRAIL $(1 \mathrm{ng} / \mathrm{ml})$ for an additional $4 \mathrm{~h}$. Whole-cell lysates were analyzed using immunoblotting assay with indicated antibodies. 
$\left(\mathrm{CHOP}^{-/-}\right)$mouse embryo fibroblast $(\mathrm{MEF})$ cell line and a PUMA knockout $\left(\mathrm{PUMA}^{-/}\right)$HCT116 cell line. As shown in Figure 7A and 7B, combinatorial treatmentinduced synergistic apoptosis was suppressed in $\mathrm{CHOP}^{-/}$ MEFs and $\mathrm{PUMA}^{-/}$cells. Moreover, the combinatorial treatment-induced synergistic apoptosis was not inhibited in p53 knockout (p53--) cells (Figure 7C). These results suggest that the p53-independent CHOP/PUMA pathway is responsible for the combinatorial treatment-induced synergistic apoptosis.
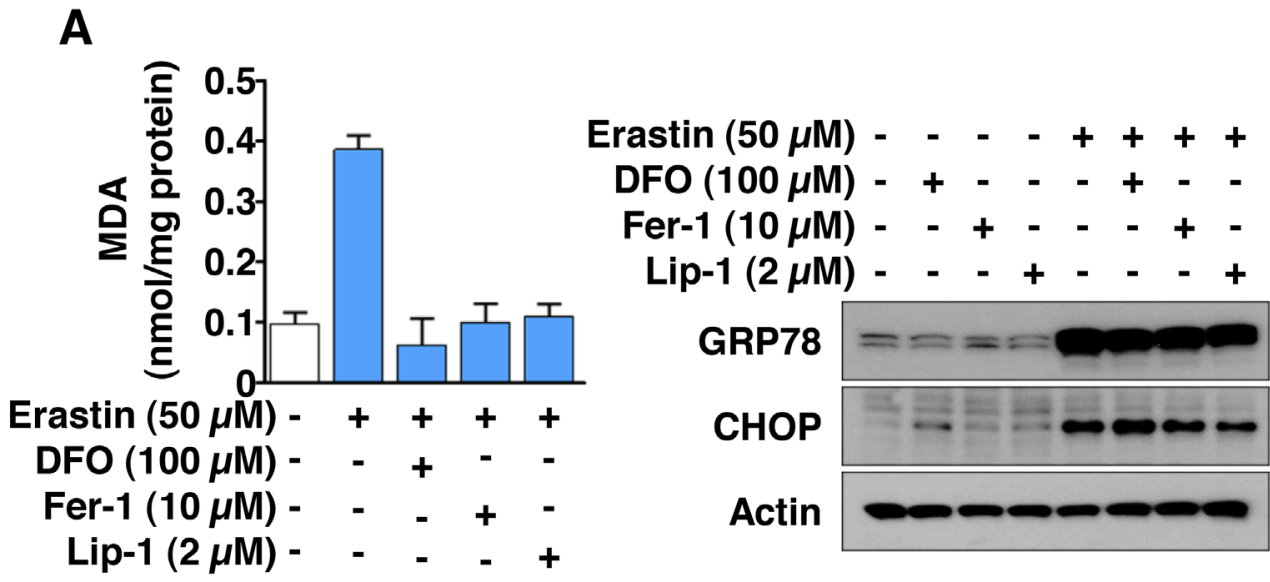

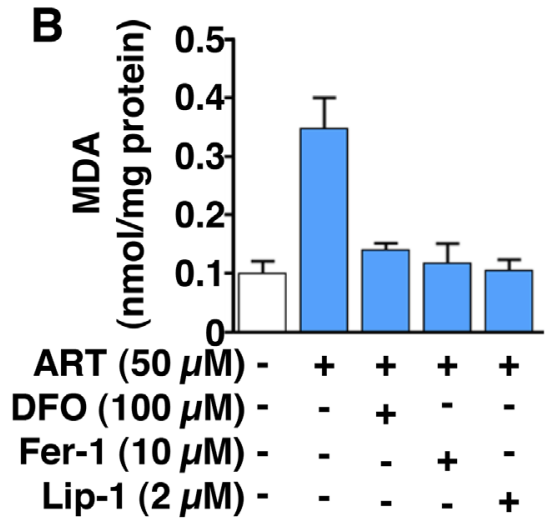

C

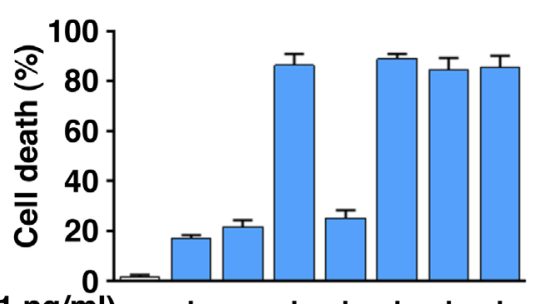

$\begin{array}{rrrrrrrrr}\text { TRAIL }(1 \mathrm{ng} / \mathrm{ml}) & - & + & - & + & + & + & + & + \\ \text { Erastin }(50 \mu \mathrm{M}) & - & - & + & + & + & + & + & + \\ \text { Z-VAD }(1 \mu \mathrm{M}) & - & - & - & - & + & - & - & - \\ \text { DFO }(100 \mu \mathrm{M}) & - & - & - & - & - & + & - & - \\ \text { Fer-1 }(10 \mu \mathrm{M}) & - & - & - & - & - & - & + & - \\ \text { Lip-1 }(2 \mu \mathrm{M}) & - & - & - & - & - & - & - & +\end{array}$

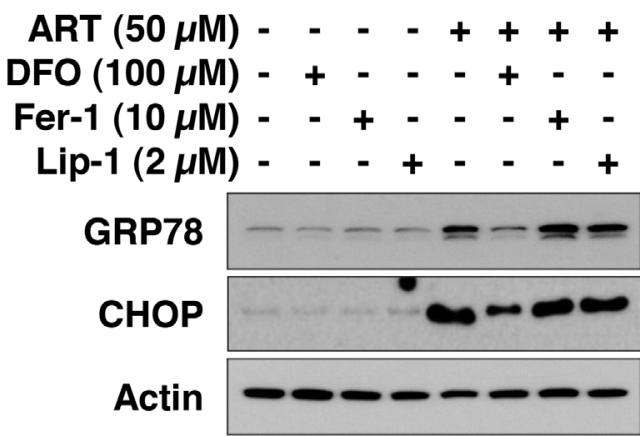

D

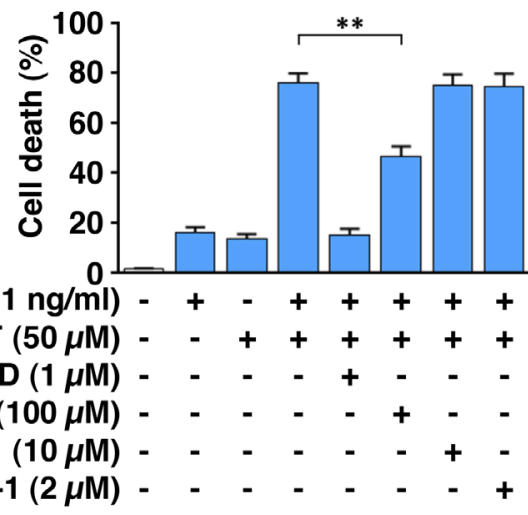

Figure 5: The combinatorial treatment of ferroptotic agent and TRAIL promotes apoptosis via ER stress, but not lipid peroxidation in HCT116 cells. (A and B) Cells were treated with $50 \mu \mathrm{M}$ erastin (A) or ART (B) for $24 \mathrm{~h}$ in the absence/presence of DFO $(100 \mu \mathrm{M})$, ferrostatin-1 (Fer-1, $10 \mu \mathrm{M})$, or liproxstatin-1 (Lip-1, $2 \mu \mathrm{M})$. Lipid peroxidation level was detected by MDA assay (left panels) and whole-cell lysates were analyzed with immunoblotting assay using indicated antibodies (right panels). (C and D) Cells were pretreated with erastin (C) and ART (D) for $20 \mathrm{~h}$ in the absence/presence of Z-VAD (1 $\mu \mathrm{M})$, DFO (100 $\mu \mathrm{M})$, Fer-1 (10 $\mu \mathrm{M})$, or Lip-1 (2 $\mu \mathrm{M})$ and then exposed to TRAIL $(1 \mathrm{ng} / \mathrm{ml})$ for an additional $4 \mathrm{~h}$. Cell death was determined using trypan blue exclusion assay and plotted. 


\section{Effect of ART and TRAIL on the growth of xenograft tumors}

In vivo studies were performed to examine the effect of the combinatorial treatment with ART and TRAIL on the growth of luciferase-expressing HCT116 xenograft tumors. For xenograft tumor formation, five-week-old male nude mice (Balb/c nude) were subcutaneously inoculated with $1 \times 10^{6} \mathrm{HCT} 116$-luc cells into the right hind leg. Prior to treatment with ART and TRAIL, tumor size was measured two to three times per week until the volume reached approximately $200 \mathrm{~mm}^{3}$. Tumor volume was calculated as $\mathrm{W}^{2} \times \mathrm{L} \times 0.52$, where $\mathrm{L}$ is the largest diameter and $\mathrm{W}$ is the diameter perpendicular to $\mathrm{L}$. After establishment of these tumor xenografts, mice were randomized into four groups of five mice per group. ART (200 mg/kg, oral gavage administration) and/ or rh-TRAIL $(100 \mu \mathrm{g} / \mathrm{kg}$, intratumoral injection) were administered twice per week for two weeks. TRAIL alone did not significantly affect tumor growth compared with the control group. ART alone caused a decrease of tumor growth $(\mathrm{p}<0.05)$. The combinatorial treatment with ART and TRAIL was significantly more effective in inhibiting tumor growth compared with single treatment $(\mathrm{p}<0.001)$ (Figure 8C). Data from terminal deoxynucleotidyl transferase (TdT) dUTP nick-end labeling (TUNEL) assay and quantitative analysis (Figure 8D and 8E) show that the combinatorial treatment effectively induced apoptosis. Although the tendency for weight loss was observed during the combined treatment of ART and TRAIL, it was not statistically significant (Figure 8F).

\section{DISCUSSION}

Several conclusions can be drawn upon consideration of the data presented in the current study. First, the combined treatment of erastin or ART and TRAIL synergistically induced apoptosis, but not ferroptosis. Second, ER stress played an important role in the synergistic apoptosis through activating the p53independent CHOP-PUMA axis.

It is well known that the ER stress response mediated by the PERK (PKR-like ER kinase)-eIF2 $\alpha$ (eukaryotic initiation factor $2 \alpha$ )-ATF4 pathway is involved in regulation of the expression of several target genes such as CHOP $[44,45]$. Data from immunoblotting assay
A

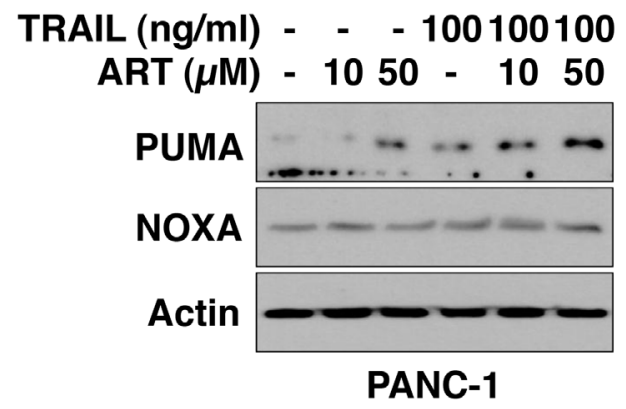

C

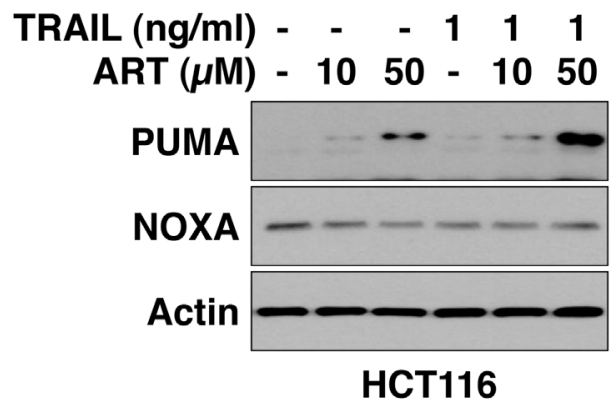

B

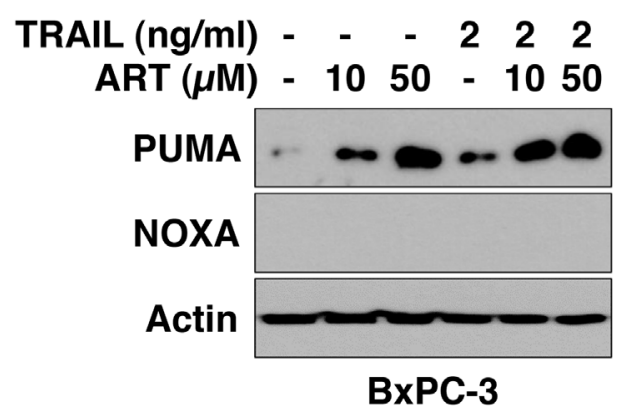

D

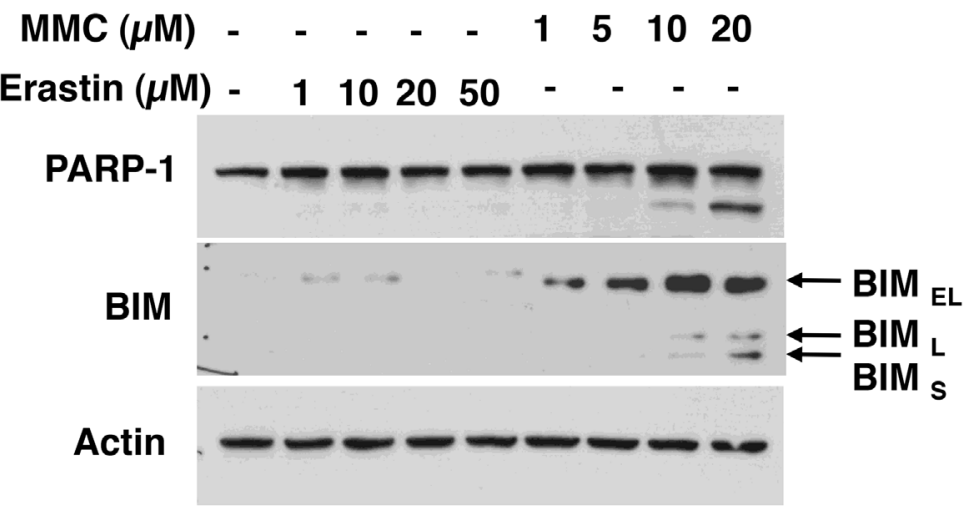

Figure 6: ART increases PUMA protein level. PANC-1 (A), BxPC-3 (B), and HCT116 (C) cells were pretreated with ART (10 or $50 \mu \mathrm{M}$ ) for $20 \mathrm{~h}$ and then exposed to TRAIL (PANC-1, $100 \mathrm{ng} / \mathrm{ml}$; BxPC-3, $2 \mathrm{ng} / \mathrm{ml}$; HCT116, $1 \mathrm{ng} / \mathrm{ml}$ ) for additional $4 \mathrm{~h}$. Whole-cell lysates were analyzed with immunoblotting assay using indicated antibodies. (D) HCT116 cells were treated with erastin (1-50 $\mu \mathrm{M})$ or mitomycin $\mathrm{C}(1-20 \mu \mathrm{M}, \mathrm{MMC})$ for $24 \mathrm{~h}$. Whole-cell lysates were analyzed with immunoblotting assay using indicated antibodies. 
confirmed an increase in expression of the ER stressrelated genes GRP78 and CHOP during ferroptotic agent treatment (Figures 4, 5, and 7). Several researchers have reported that ER stress induces apoptosis through inducing
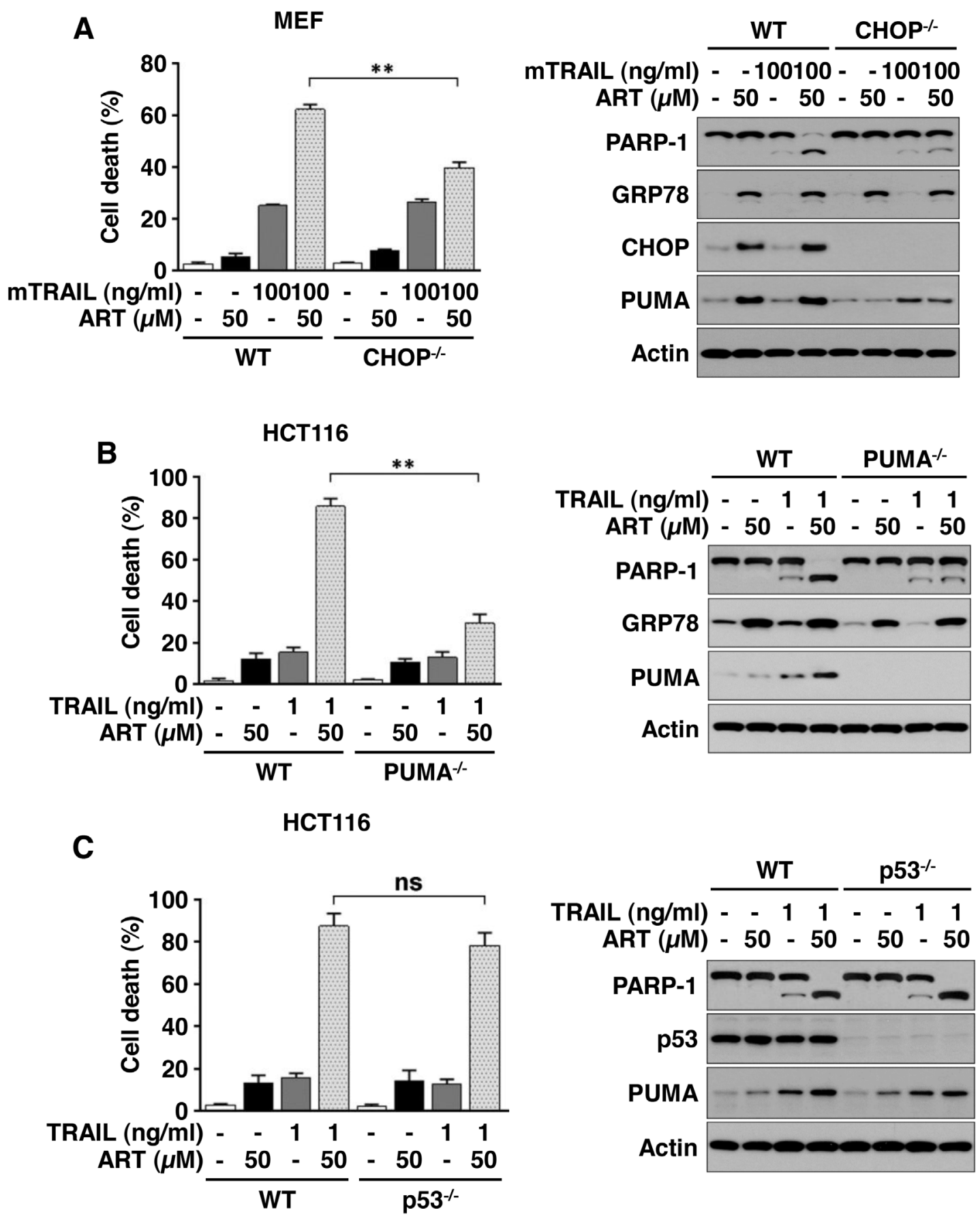

Figure 7: ART promotes TRAIL-induced apoptosis via the p53-independent CHOP/PUMA pathway. (A) Mouse embryonic fibroblasts (MEFs) wild-type (WT) or MEF CHOP knockout (KO) cells were pretreated with ART (10 or $50 \mu \mathrm{M})$ for $20 \mathrm{~h}$ and then exposed to recombinant murine TRAIL (mTRAIL; $100 \mathrm{ng} / \mathrm{ml}$ ) for an additional $4 \mathrm{~h}$. Cell death was determined using trypan blue exclusion assay and plotted (left panel). Whole-cell extracts were analyzed with immunoblotting assay using indicated antibodies (right panel). (B) HCT116 WT or HCT116 PUMA KO cells were pretreated with ART (10 or $50 \mu \mathrm{M})$ for $20 \mathrm{~h}$ and then exposed to TRAIL $(1 \mathrm{ng} / \mathrm{ml})$ for additional $4 \mathrm{~h}$. Cell death was determined by counting and plotted (left panel). Whole-cell extracts were then analyzed with immunoblotting using indicated antibodies (right panel). (C) HCT116 WT or HCT116 p53 KO cells were pretreated with ART (10 or 50 $\mu \mathrm{M})$ for $20 \mathrm{~h}$ and then exposed to TRAIL $(1 \mathrm{ng} / \mathrm{ml}$ ) for an additional $4 \mathrm{~h}$. Cell death was determined using trypan blue exclusion assay and plotted (left panel). Whole-cell extracts were then analyzed with immunoblotting assay using indicated antibodies (right panel). 
pro-apoptotic proteins such as PUMA, NOXA, GADD34 (growth arrest and DNA damage-inducible protein), ERO1 $\alpha$ (endoplasmic reticulum, oxidoreductin- $1 \alpha$ ), and BIM (Bcl-2-like protein 11) [41, 42]. However, unlike previous reports, we observed an increase in expression of PUMA, but not NOXA and BIM, during treatment with ferroptotic agent (Figure 6). This discrepancy needs further investigation. Presently, we can only speculate on the differential expression in ER response-inducible proapoptotic gene expression during treatment with ferroptotic agent. Several transcription factors are known to regulate transcription of PUMA and NOXA gene expression: p53, c-Myc, forkhead box O3A (FoxO3A), p65 or p52 subunit of nuclear factor- $\kappa \mathrm{B}, \mathrm{p} 73, \mathrm{CHOP}$, $\mathrm{E} 2 \mathrm{~F} 1, \mathrm{C} / \mathrm{EBP} \beta$ (CCAAT-enhancer-binding proteins), CREB (cAMP response element-binding protein), c-Jun, and Sp1 for PUMA gene expression [46], and HIF-1 $\alpha$, E2F1, c-myc, p53, p73, and ATF4 for NOXA gene expression [47]. They may share the same transcription factors for p53-dependent expression of these genes by genotoxic stress, but not in p53-independent expression of these genes by other stimuli.

In the present study, we report that Fer-1 and Lip-1 (inhibitors of ferroptosis), when combined with TRAIL, still suppressed ferroptosis but not synergistic apoptosis and ER stress. However, unlike Fer-1 and Lip1, the different ferroptosis inhibitor DFO inhibited ARTinduced ER stress exclusive of that induced by erastin as well as synergistic apoptosis (Figure 5). This was probably due to differences in mechanisms by which each ferroptosis inducer contributes to the various metabolic derangements that lead ultimately to ER stress. Since
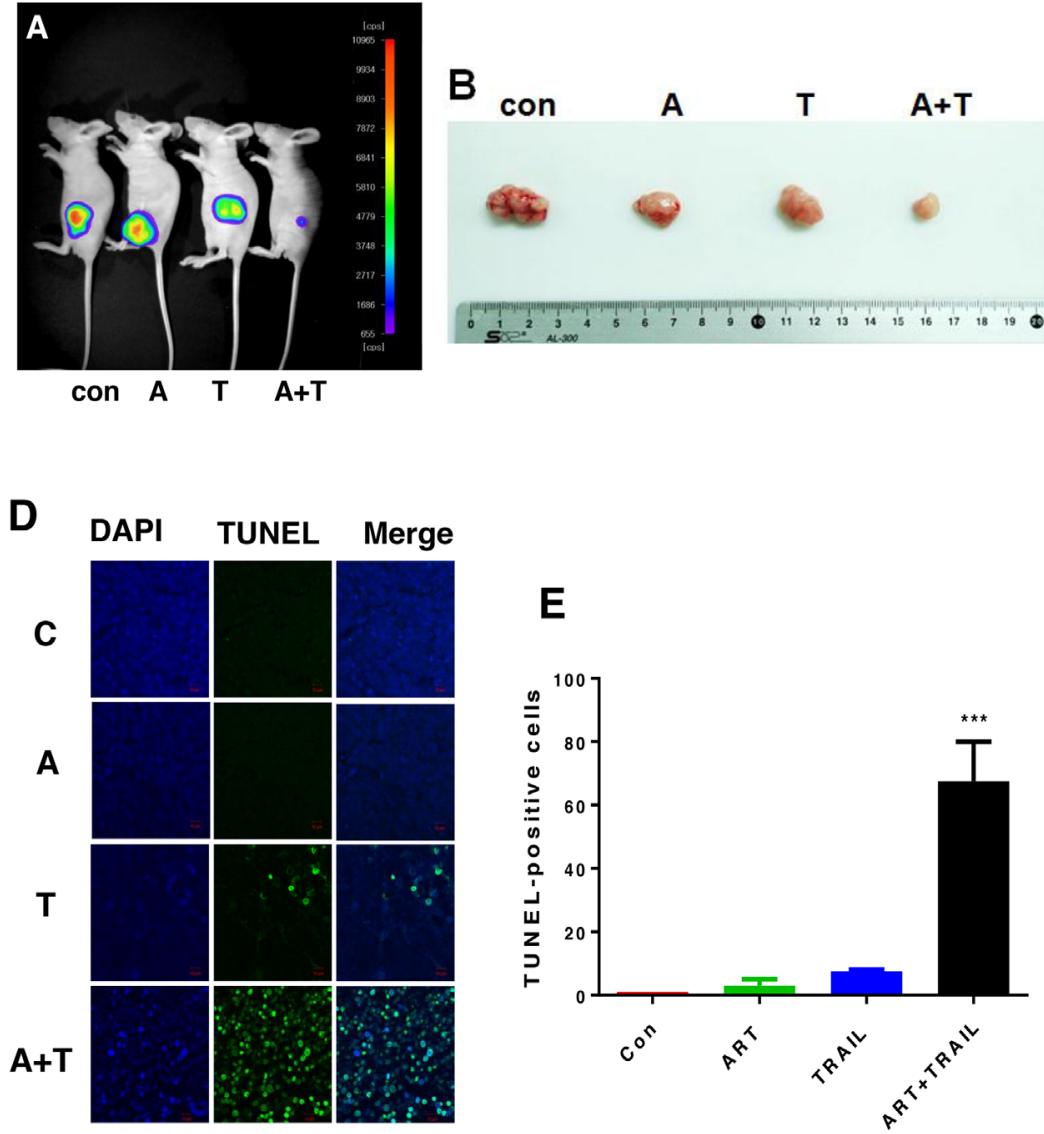

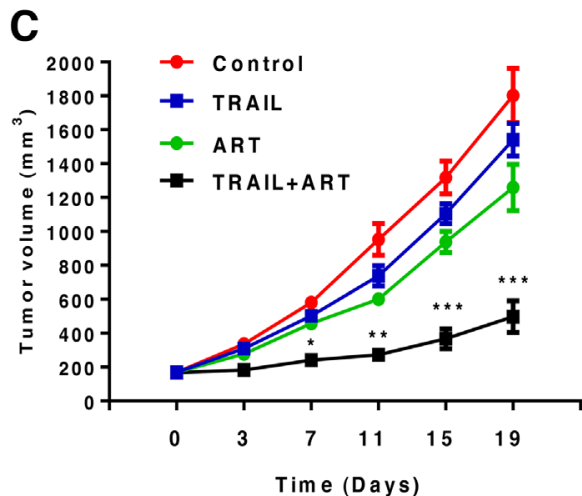

$\mathbf{F}$

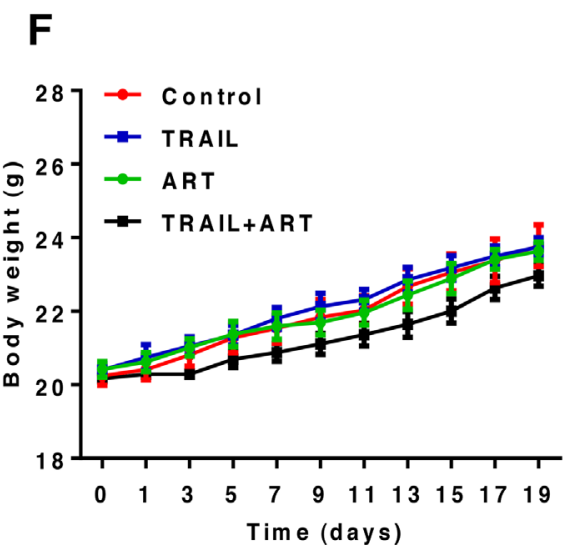

Figure 8: The combinatorial treatment of ART and TRAIL synergistically inhibits tumor growth. Nude mice were subcutaneously inoculated with $1 \times 10^{6} \mathrm{HCT} 116$-luc cells. When the tumor volume reached approximately $200 \mathrm{~mm}^{3}$, tumor bearing mice were treated with ART (A, $200 \mathrm{mg} / \mathrm{kg}$, twice per week, oral gavage) alone, TRAIL (T, $100 \mu \mathrm{g} / \mathrm{kg}$, twice per week, intra-tumoral) alone, or the combination of ART and TRAIL (A + T). (A) Mice were imaged using the NightOWL LB983 bioluminescence imaging (BLI) system. Representative images are shown on day 19. (B) Tumor tissues were harvested on day 19 and displayed. (C) Line graph illustrating the tumor volume $\left(\mathrm{mm}^{3}\right)$ in HCT116-luc tumor-bearing mice treated with PBS alone, ART alone, TRAIL alone, or the combination from day 0 to day 19. Error bars represent the mean \pm SD from five mice. For statistical analysis, Student's $t$-test (two-sided, paired) was used. $p$-values: ${ }^{*}, 0.05 ;{ }^{* *}, 0.01 ;{ }^{* * *}, 0.001$. (D and E) Tumor tissues were harvested on day 19 and subjected to TUNEL assay and DAPI (4',6-diamidino2-phenylindole) staining. Cell nuclei were stained with DAPI. Apoptosis was detected using TUNEL assay (D) and percents of TUNELpositive cells were plotted (E). (F) Line graph illustrating the body weight (gram) in HCT116-luc tumor-bearing mice treated with PBS alone, ART alone, TRAIL alone, or the combination from day 0 to day 19 . 
DFO has pleiotropic effects (inhibition of iron-mediated lipid peroxidation, inhibition of $\mathrm{NF}-\kappa \mathrm{B}$ activation, and involvement in several peroxidative systems [48, 49]), DFO may affect ART-induced ER stress and its activation of NF- $\kappa \mathrm{B}$ by preventing $\mathrm{I} \kappa \mathrm{B} \alpha$ degradation $[48,50,51]$. Obviously, further studies are necessary to understand the molecular mechanism of differences between each ferroptosis inducer-induced ER stress.

Although the ferroptotic agent erastin and ART induced pro-apoptotic protein PUMA expression (Figures 6 and 7), unlike in previous reports, erastin and ART did not induce apoptosis; the caspase substrate PARP-1, a hallmark feature of apoptosis, was not cleaved during ferroptotic agent treatment (Figures 1 and 2). These results suggest that ferroptotic agent-induced PUMA remains inactive during treatment with ferroptotic agent alone and then switches to an active state during combinatorial treatment with ferroptotic agent and TRAIL. Previous biochemical studies indicate that PUMA induces apoptosis by activating the multidomain proapoptotic protein Bax and/or Bak through its interaction with antiapoptotic Bcl-2 family members such as Bcl-2 (B-cell lymphoma 2) and $\mathrm{Bcl}-\mathrm{xL}$ (B-cell lymphoma-extra large), thereby triggering mitochondrial dysfunction, cytochrome $c$ release, and caspase activation [46]. How ferroptotic agent-induced PUMA sustains a biochemically inactive state during treatment with ferroptotic agent alone is a question that remains unanswered. It is possible that ferroptotic agentinduced PUMA remains inactive through binding with anti-apoptotic Bcl-2 family members (Bcl-2, Bcl-xL, Mcl-1) as well as Beclin-1. During combinatorial treatment with ferroptotic agent and TRAIL, Beclin-1 is cleaved by TRAIL-activated caspase 8 [52] and the cleavage of Beclin-1 leads to PUMA changing from an inactive to an active state. The conversion of PUMA from an inactive to an active state results in an increase in apoptosis. Another possibility is the apoptotic threshold effect [53]. Apoptosis occurs when an apoptotic threshold is reached, owing to the inhibition of Bcl-2, Bcl-xL, and Mcl-1 by PUMA [53]. A combinatorial treatment of ferroptotic agent and TRAIL induces the level of PUMA at which apoptosis occurs above a threshold. Obviously, these possibilities need to be further examined to understand the role of PUMA in the combinatorial treatment-induced synergistic apoptosis.

\section{MATERIALS AND METHODS}

\section{Cell lines and cell culture conditions}

Human pancreatic cancer PANC-1 and BxPC-3 cells and human colon cancer HCT116 cells were previously obtained from American Type Culture Collection (ATCC, Manassas, VA). PUMA-deficient $\left(\mathrm{PUMA}^{-/}\right)$and $\mathrm{p} 53-$

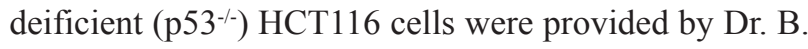
Vogelstein (Johns Hopkins University, Baltimore, MD). $\mathrm{CHOP}$-deficient $\left(\mathrm{CHOP}^{-/}\right)$and corresponding wild-type
(WT) MEF cell lines were provided by Dr. Randal J. Kaufman (Sanford Burnham Medical Research Institute, CA). Each cell line was maintained in a medium as follows: HCT116 cells in McCoy's 5A; PANC-1 cells and MEFs in Dulbecco's Modified Eagle Medium (DMEM); BxPC-3 cells in Roswell Park Memorial Institute (RPMI)1640 supplemented with $2 \mathrm{mM}$ glutamine. All cell lines were maintained with $10 \%$ fetal bovine serum (FBS) and incubated in a humidified atmosphere of $5 \% \mathrm{CO}_{2}$ at $37^{\circ} \mathrm{C}$.

\section{Chemicals and reagents}

For production of recombinant human TRAIL, a human TRAIL cDNA fragment (amino acids 114-281) obtained by RT-PCR was cloned into a pET-23d plasmid (Novagen, Madison, WI), and His-tagged TRAIL protein was purified using the Qiagen express protein purification system (Qiagen, Valencia, CA). Soluble recombinant murine TRAIL and cell-permeant pan caspase inhibitor Z-VAD-FMK were purchased from R\&D systems (Minneapolis, MN). Liproxstatin-1, deferoxamine, and ferrostatin-1 were obtained from Sigma-Aldrich (St. Louis, MO). Artesunate, erastin, and mitomycin $\mathrm{C}$ were purchased from Selleckchem (Houston, TX).

\section{Microarray assay}

HCT116 cells were treated with $50 \mu \mathrm{M}$ ART for 24 $\mathrm{h}$ and total RNA was extracted using the RNeasy mini kit (Qiagen, Valencia, CA) according to the manufacturer's instructions. RNA quality and integrity were verified using the Agilent 2100 Bioanalyzer system (Agilent Technologies, Santa Clara, CA). Biotin-labeled cRNA samples for hybridization on Illumina HumanHT-12 v4 Expression BeadChip (Illumina, Inc., San Diego, CA) were prepared according to Illumina's recommended sample labeling procedure.

\section{Lipid peroxidation assay}

To measure the concentration of MDA, one of the end products of lipid peroxidation, colorimetric analysis of lipid ROS production was carried out using a Lipid Peroxidation (MDA) Assay Kit (\#MAK085, SigmaAldrich) according to the manufacturer's instructions. MDA-TBA adduct was quantified colorimetrically at $532 \mathrm{~nm}$ using a spectrophotometer.

\section{Apoptosis assay by flow cytometry}

To detect the translocation of phosphatidylserine, one of the markers of apoptosis, from the inner to the outer leaflet of the plasma membrane, cells were stained with Annexin V according to the manufacturer's protocol of the fluorescein isothiocyanate Annexin V Apoptosis Detection Kit (BD Biosciences, San Diego, CA). Flow cytometry was performed using an Accuri C6 flow cytometer (BD Biosciences). 


\section{Cell death and viability assay}

Cell death was typically measured using trypan blue exclusion assay to detect plasma membrane integrity as previously described [54]. For quantification of cell death rate, cells were trypsinized and stained with trypan blue followed by counting with a hemocytometer under microscope. In some experiments, propidium iodide staining was performed. Red-stained cells were considered dead. Quantification of cell death was further confirmed using flow cytometry. Cell viability was typically assessed in 96-well format with Alamar Blue Cell Viability Assay Kit (Invitrogen, Carlsbad, CA) according to the manufacturer's instructions.

\section{Western blotting and antibodies}

Immunoblotting was carried out as previously described [55]. The following antibodies were used in this study: anti-PARP-1, anti-cleaved caspase-3, anti-cleaved caspase-8, anti-caspase- 9 , anti-cleaved caspase- 9 , antiHO-1, anti-NOXA, anti-CHOP, anti-GRP78, anti-PUMA (Cell signaling Technology, Beverly, MA), anti-actin (MP Biomedicals, Solon, $\mathrm{OH}$ ), goat anti-rabbit IgG-horseradish peroxidase (HRP), and goat anti-mouse IgG-HRP (Santa Cruz Biotechnology, Santa Cruz, CA).

\section{Combination index (CI) analysis}

CIs were calculated using the CompuSyn software (ComboSyn, Inc., Paramus, NJ, USA). Base on CI values, the extent of synergism/antagonism was determined. In general, CI values below 1 suggest synergy, whereas CI values above 1 indicate antagonism between the drugs. CI values in the $0.9-1.10$ range mainly indicate additive effects, those between 0.9-0.85 suggest slight synergy, those in the range of 0.7-0.3 indicate moderate synergy, and those less than 0.3 suggest strong synergy.

\section{Animal model}

Human colon adenocarcinoma HCT116-Luc cells were established by subcutaneously injecting $10^{6}$ cells into the right hind leg of five-week-old male nude mice (Balb/c nude) (Charles River Labs, Wilmington, MA, USA). Prior to treatment with ART and TRAIL, tumor size was measured two to three times per week until the volume reached approximately $200 \mathrm{~mm}^{3}$. Tumor volume was calculated as $\mathrm{W}^{2} \times \mathrm{L} \times 0.52$ where $\mathrm{L}$ is the largest diameter and $\mathrm{W}$ is the diameter perpendicular to $\mathrm{L}$. After establishment of these tumor xenografts, mice were randomized into four groups of five mice per group. Mice were fed ad libitum and maintained in environments with controlled temperature of $22-24^{\circ} \mathrm{C}$ and $12 \mathrm{~h}$ light and dark cycles. Artesunate group: $200 \mathrm{mg} / \mathrm{kg}$-twice per week - oral gavage - two-week treatment rhTRAIL group:
$100 \mathrm{ng} / \mathrm{g}$-twice per week - intra-tumoral injection - twoweek treatment. Animals were anesthetized and subjected to NightOWL LB983 bioluminescence imaging (BLI) system (Berthold Technologies, TN, USA). D-luciferin sodium salt (BioVision Inc. Milpitas, CA) at $100 \mathrm{mg} / \mathrm{kg}$ was administered intraperitoneally as a substrate before BLI imaging. The captured images were quantified using the IndiGo ${ }^{\mathrm{TM}}$ software package. All animal procedures were carried out in accordance with guidelines approved by the Korea University Institutional Animal Care and Use Committee (IACUC).

\section{Statistical analysis}

All the values are represented as mean \pm S.D. Statistical analysis was performed one-way analysis of variance (ANOVA) followed by Bonferroni's test or by the Student's $t$-test as indicated using GraphPad Prism 7 software. $P$ value less than 0.05 was defined as statistical significance. Where indicated ${ }^{*} p<0.05 ;{ }^{* *} p<0.01$; ${ }^{* * *} p<0.001$.

\section{Abbreviations}

Apaf1: apoptosis signal-regulating kinase, ART: artesunate, ATCC: American Tissue Type Culture Collection, ATF4: activating transcription factor 4, Bak: Bcl-2 homologous antagonist killer, Bax: Bcl-2-associated $\mathrm{X}$ protein, Bcl-2: B-cell lymphoma 2, Bcl-xL: B-cell lymphoma-extra large, BH3: Bcl-2 homology domain 3, Bim: Bcl-2-like protein 11, BLI: bioluminescence imaging, BSO: buthionine sulfoximine, C/EBP: CCAATenhancer-binding proteins, CHAC1: glutathionespecific gamma-glutamylcyclotransferase 1, CHOP: CCAAT-enhancer-binding protein homologous protein, CREB: cAMP response element-binding protein, DAPI: 4',6-diamidino-2-phenylindole, DD: death domain, DFO: deferoxamine, DISC: death-inducing signaling complex, DR: death receptor, DR4: death receptor 4, DR5: death receptor 5, eIF2 $\alpha$ : eukaryotic initiation factor $2 \alpha$, ER: endoplasmic reticulum, ERO1 $\alpha$ : endoplasmic reticulum, oxidoreductin-1 $\alpha$, FACS: fluorescence-activated cell sorting, FBS: fetal bovine serum, Fer-1: ferrostatin-1, FITC: fluorescein isothiocyanate, FoxO3A: forkhead box O3A, GADD34: growth arrest and DNA damage-inducible protein, GPX4: glutathione peroxidase 4, GRP78: 78 kDa glucose regulated protein, GSH: glutathione, HO-1: heme oxygenase-1, KI: knock-in, KO: knockout, Lip-1: liproxstatin-1, MDA: malondialdehyde, MEF: mouse embryo fibroblast, PARP: poly (ADP-ribose) polymerase, PBS: phosphate-buffered saline solution, PERK: PKR-like ER kinase, PI: propidium iodide, PUMA: p53 upregulated modulator of apoptosis, RPMI: Roswell Park Memorial Institute medium, ROS: reactive oxygen species, tBid: truncated Bid, TRAIL: tumor necrosis factor-related apoptosis-inducing ligand, TRB3: tribbles homolog 3, 
Ub: ubiquitin, UPR: unfolded protein response, VDAC2/3: voltage-dependent anion channel 2/3, WT: wild-type.

\section{Author contributions}

Data collection: S.H.H, D.H.L, M.J.J, Y.A.J, W.T.K; Conception/design of the work: M.H.A.C, D.L.B, Y.J.L; Data analysis and interpretation: S.H.H, Y.J.L; Drafting the article: Y.J.L.

\section{ACKNOWLEDGMENTS}

This work was supported by the following grants: National Cancer Institute (NCI) grants R03 CA205267 and R03 CA212125 (Y.J.L.), and National Research Foundation (NRF) of Korea grant NRF2015R1D1A1A01058303 (D.H.L.). This project used the University of Pittsburgh Cancer Institute Core Facility and was supported in part by award P30CA047904.

\section{CONFLICTS OF INTEREST}

The authors declare no competing financial interest.

\section{GRANT SUPPORT}

NCI R03CA205267, R03CA212125, and P30CA047904.

\section{REFERENCES}

1. Fink SL, Cookson BT. Apoptosis, pyroptosis, and necrosis: mechanistic description of dead and dying eukaryotic cells. Infect Immun. 2005; 73:1907-1916.

2. Nikoletopoulou V, Markaki M, Palikaras K, Tavernarakis N. Crosstalk between apoptosis, necrosis and autophagy. Biochimica et Biophysica Acta. 2013; 1833:3448-3459.

3. Dixon SJ, Lemberg KM, Lamprecht MR, Skouta R, Zaitsev EM, Gleason CE, Patel DN, Bauer AJ, Cantley AM, Yang WS, Morrison B 3rd, Stockwell BR. Ferroptosis: an irondependent form of nonapoptotic cell death. Cell. 2012; 149:1060-1072.

4. Magtanong L, Ko PJ, Dixon SJ. Emerging roles for lipids in non-apoptotic cell death. Cell Death Differ. 2016; 23:1099-1109.

5. Shimada K, Skouta R, Kaplan A, Yang WS, Hayano M, Dixon SJ, Brown LM, Valenzuela CA, Wolpaw AJ, Stockwell BR. Global survey of cell death mechanisms reveals metabolic regulation of ferroptosis. Nat Chem Biol. 2016; 12:497-503.

6. Yang WS, Stockwell BR. Synthetic lethal screening identifies compounds activating iron-dependent, nonapoptotic cell death in oncogenic-RAS-harboring cancer cells. Chem Biol. 2008; 15:234-245.

7. Friedmann Angeli JP, Schneider M, Proneth B, Tyurina YY, Tyurin VA, Hammond VJ, Herbach N, Aichler M, Walch A,
Eggenhofer E, Basavarajappa D, Rådmark O, Kobayashi $\mathrm{S}$, et al. Inactivation of the ferroptosis regulator $\mathrm{Gpx} 4$ triggers acute renal failure in mice. Nat Cell Biol. 2014; 16:1180-1191.

8. Yang WS, SriRamaratnam R, Welsch ME, Shimada K, Skouta R, Viswanathan VS, Cheah JH, Clemons PA, Shamji AF, Clish CB, Brown LM, Girotti AW, Cornish VW, et al. Regulation of ferroptotic cancer cell death by GPX4. Cell. 2014; 156:317-331.

9. Conrad M, Friedmann Angeli JP. Glutathione peroxidase 4 (Gpx4) and ferroptosis: what's so special about it? Mol Cell Oncol. 2015; 2:e995047.

10. Xie Y, Hou W, Song X, Yu Y, Huang J, Sun X, Kang R, Tang D. Ferroptosis: process and function. Cell Death Differ. 2016; 23:369-379.

11. Lisewski AM, Quiros JP, Ng CL, Adikesavan AK, Miura K, Putluri N, Eastman RT, Scanfeld D, Regenbogen SJ, Altenhofen L, Llinás M, Sreekumar A, Long C, et al. Supergenomic network compression and the discovery of EXP1 as a glutathione transferase inhibited by artesunate. Cell. 2014; 158:916-928.

12. Yang WS, Kim KJ, Gaschler MM, Patel M, Shchepinov MS, Stockwell BR. Peroxidation of polyunsaturated fatty acids by lipoxygenases drives ferroptosis. Proc Natl Acad Sci U S A. 2016; 113:E4966-E4975.

13. Yang WS, Stockwell BR. Ferroptosis: death by lipid peroxidation. Trends Cell Biol. 2016; 26:165-176.

14. Schott C, Graab U, Cuvelier N, Hahn H, Fulda S. Oncogenic RAS mutants confer resistance of RMS13 rhabdomyosarcoma cells to oxidative stress-induced ferroptotic cell death. Front Oncol. 2015; 5:131.

15. Cao JY, Dixon SJ. Mechanisms of ferroptosis. Cell Mol Life Sci. 2016; 73:2195-2209.

16. Jiang L, Kon N, Li T, Wang SJ, Su T, Hibshoosh H, Baer R, $\mathrm{Gu}$ W. Ferroptosis as a p53-mediated activity during tumour suppression. Nature. 2015; 520:57-62.

17. Wang SJ, Li D, Ou Y, Jiang L, Chen Y, Zhao Y, Gu W. Acetylation is crucial for p53-mediated ferroptosis and tumor suppression. Cell Rep. 2016; 17:366-373.

18. Murphy ME. Ironing out how p53 regulates ferroptosis. Proc Natl Acad Sci U S A. 2016; 113:12350-12352.

19. Yagoda N, von Rechenberg M, Zaganjor E, Bauer AJ, Yang WS, Fridman DJ, Wolpaw AJ, Smukste I, Peltier JM, Boniface JJ, Smith R, Lessnick SL, Sahasrabudhe S, et al. RAS-RAFMEK-dependent oxidative cell death involving voltagedependent anion channels. Nature. 2007; 447:864-868.

20. Skouta R, Dixon SJ, Wang J, Dunn DE, Orman M, Shimada K, Rosenberg PA, Lo DC, Weinberg JM, Linkermann A, Stockwell BR. Ferrostatins inhibit oxidative lipid damage and cell death in diverse disease models. J Am Chem Soc. 2014; 136:4551-4556.

21. Ma S, Henson ES, Chen Y, Gibson SB. Ferroptosis is induced following siramesine and lapatinib treatment of breast cancer cells. Cell Death Dis. 2016; 7:e2307. 
22. Liu Y, Wang W, Li Y, Xiao Y, Cheng J, Jia J. The 5-lipoxygenase inhibitor zileuton confers neuroprotection against glutamate oxidative damage by inhibiting ferroptosis. Biol Pharm Bull. 2015; 38:1234-1239.

23. Dächert J, Schoeneberger H, Rohde K, Fulda S. RSL3 and Erastin differentially regulate redox signaling to promote Smac mimetic-induced cell death. Oncotarget. 2016; 7:63779-63792. https://doi.org/10.18632/oncotarget.11687.

24. Ashkenazi A, Dixit VM. Apoptosis control by death and decoy receptors. Curr Opin Cell Biol. 1999; 11:255-260.

25. Walczak H, Miller RE, Ariail K, Gliniak B, Griffith TS, Kubin M, Chin W, Jones J, Woodward A, Le T, Smith C, Smolak P, Goodwin RG, et al. Tumoricidal activity of tumor necrosis factor-related apoptosis-inducing ligand in vivo. Nat Med. 1999; 5:157-163.

26. Ganten TM, Haas TL, Sykora J, Stahl H, Sprick MR, Fas SC, Krueger A, Weigand MA, Grosse-Wilde A, Stremmel W, Krammer PH, Walczak H. Enhanced caspase-8 recruitment to and activation at the DISC is critical for sensitisation of human hepatocellular carcinoma cells to TRAIL-induced apoptosis by chemotherapeutic drugs. Cell Death Differ. 2004; 11:S86-S96.

27. Li P, Nijhawan D, Budihardjo I, Srinivasula SM, Ahmad M, Alnemri ES, Wang X. Cytochrome c and dATP-dependent formation of Apaf-1/caspase-9 complex initiates an apoptotic protease cascade. Cell. 1997; 91:479-489.

28. Wei MC, Lindsten $\mathrm{T}$, Mootha VK, Weiler S, Gross A, Ashiya M, Thompson CB, Korsmeyer SJ. tBID, a membrane-targeted death ligand, oligomerizes BAK to release cytochrome c. Genes Dev. 2000; 14:2060-2071.

29. Grinberg M, Sarig R, Zaltsman Y, Frumkin D, Grammatikakis N, Reuveny E, Gross A. tBID Homooligomerizes in the mitochondrial membrane to induce apoptosis. J Biol Chem. 2002; 277:12237-12245.

30. Eskes R, Desagher S, Antonsson B, Martinou JC. Bid induces the oligomerization and insertion of Bax into the outer mitochondrial membrane. Mol Cell Biol. 2000; 20:929-935.

31. Baliga B, Kumar S. Apaf-1/cytochrome c apoptosome: an essential initiator of caspase activation or just a sideshow? Cell Death Differ. 2003; 10:16-18.

32. Keane MM, Ettenberg SA, Nau MM, Russell EK, Lipkowitz S. Chemotherapy augments TRAIL-induced apoptosis in breast cell lines. Cancer Res. 1999; 59:734-741.

33. Nagane M, Pan G, Weddle JJ, Dixit VM, Cavenee WK, Huang HJ. Increased death receptor 5 expression by chemotherapeutic agents in human gliomas causes synergistic cytotoxicity with tumor necrosis factor-related apoptosis-inducing ligand in vitro and in vivo. Cancer Res. 2000; 60:847-853.

34. Kim YH, Lee YJ. Time sequence of tumor necrosis factorrelated apoptosis-inducing ligand (TRAIL) and cisplatin treatment is responsible for a complex pattern of synergistic cytotoxicity. J Cell Biochem. 2006; 98:1284-1295.
35. Chinnaiyan AM, Prasad U, Shankar S, Hamstra DA, Shanaiah M, Chenevert TL, Ross BD, Rehemtulla A. Combined effect of tumor necrosis factor-related apoptosisinducing ligand and ionizing radiation in breast cancer therapy. Proc Nat Acad Sci U S A. 2000; 97:1754-1759.

36. Park SY, Billiar TR, Seol DW. IFN-gamma inhibition of TRAIL-induced IAP-2 upregulation, a possible mechanism of IFN-gamma-enhanced TRAIL-induced apoptosis. Biochem Biophys Res Commun. 2002; 291:233-236.

37. Nyormoi O, Mills L, Bar-Eli M. An MMP-2/MMP-9 inhibitor, 5a, enhances apoptosis induced by ligands of the TNF receptor superfamily in cancer cells. Cell Death Differ. 2003; 10:558-569.

38. Dixon SJ, Patel DN, Welsch M, Skouta R, Lee ED, Hayano M, Thomas AG, Gleason CE, Tatonetti NP, Slusher BS, Stockwell BR. Pharmacological inhibition of cystineglutamate exchange induces endoplasmic reticulum stress and ferroptosis. Elife. 2014; 3:e2523.

39. Rahmani M, Davis EM, Crabtree TR, Habibi JR, Nguyen TK, Dent P, Grant S. The kinase inhibitor sorafenib induces cell death through a process involving induction of endoplasmic reticulum stress. Mol Cell Biol. 2007; 27:5499-5513.

40. Ohoka N, Yoshii S, Hattori T, Onozaki K, Hayashi H. TRB3, a novel ER stress-inducible gene, is induced via ATF4-CHOP pathway and is involved in cell death. EMBO J. 2005; 24:1243-1255.

41. Ghosh AP, Klocke BJ, Ballestas ME, Roth KA. CHOP potentially co-operates with FOXO3a in neuronal cells to regulate PUMA and BIM expression in response to ER stress. PLoS One. 2012; 7:e39586.

42. Urra H, Dufey E, Lisbona F, Rojas-Rivera D, Hetz C. When ER stress reaches a dead end. Biochim Biophys Acta. 2013; 1833:3507-3517.

43. Puthalakath H, O'Reilly LA, Gunn P, Lee L, Kelly PN, Huntington ND, Hughes PD, Michalak EM, McKimmBreschkin J, Motoyama N, Gotoh T, Akira S, Bouillet P, et al. ER stress triggers apoptosis by activating BH3-only protein Bim. Cell. 2007; 129:1337-1349.

44. $\mathrm{Su}$ N, Kilberg MS. C/EBP homology protein (CHOP) interacts with activating transcription factor 4 (ATF4) and negatively regulates the stress-dependent induction of the asparagine synthetase gene. J Biol Chem. 2008; 283:35106-35117.

45. Saito A, Ochiai K, Kondo S, Tsumagari K, Murakami T, Cavener DR, Imaizumi K. Endoplasmic reticulum stress response mediated by the PERK-eIF2(alpha)-ATF4 pathway is involved in osteoblast differentiation induced by BMP2. J Biol Chem. 2011; 286:4809-4818.

46. Yu J, Zhang L. PUMA, a potent killer with or without p53. Oncogene. 2008; 27:S71-S83.

47. Albert MC, Brinkmann K, Kashkar H. Noxa and cancer therapy: tuning up the mitochondrial death machinery in response to chemotherapy. Mol Cell Oncol. 2014; 1:e29906. 
48. Bowie AG, Moynagh PN, O’Neill LA. Lipid peroxidation is involved in the activation of NF-kappaB by tumor necrosis factor but not interleukin-1 in the human endothelial cell line ECV304. Lack of involvement of $\mathrm{H}_{2} \mathrm{O}_{2}$ in NF- $\mathrm{NB}$ activation by either cytokine in both primary and transformed endothelial cells. J Biol Chem. 1997; 272:25941-25950.

49. Kanner J, Harel S. Desferrioxamine as an electron donor. Inhibition of membranal lipid peroxidation initiated by $\mathrm{H}_{2} \mathrm{O}_{2}$-activated metmyoglobin and other peroxidizing systems. Free Radic Res Commun. 1987; 3:309-317.

50. Tam AB, Mercado EL, Hoffmann A, Niwa M. ER stress activates NF- $\kappa B$ by integrating functions of basal IKK activity, IRE1 and PERK. PLoS One. 2012; 7:e45078.

51. Yu L, Chen JF, Shuai X, Xu Y, Ding Y, Zhang J, Yang W, Liang X, Su D, Yan C. Artesunate protects pancreatic beta cells against cytokine-induced damage via SIRT1 inhibiting $\mathrm{NF}-\kappa \mathrm{B}$ activation. J Endocrinol Invest. 2016; 39:83-91.

52. Li H, Wang P, Sun Q, Ding WX, Yin XM, Sobol RW, Stolz DB, Yu J, Zhang L. Following cytochrome c release, autophagy is inhibited during chemotherapy-induced apoptosis by caspase 8-mediated cleavage of Beclin 1 . Cancer Res. 2011; 71:3625-3634.

53. Khoo KH, Verma CS, Lane DP. Drugging the $\mathrm{p} 53$ pathway: understanding the route to clinical efficacy. Nat Rev Drug Discov. 2014; 13:217-236.

54. Strober W. Trypan blue exclusion test of cell viability. Curr Protoc Immunol. 2001; Appendix 3: Appendix 3B.

55. Gallagher S, Chakavarti D. Immunoblot analysis. J Vis Exp. 2008; 16:759. 